Utah State University

DigitalCommons@USU

$1-1-2011$

\title{
Characterization of a Quantum Cascade Laser Based Emissivity Monitor for CORSAIR
}

\author{
Maung Lwin \\ Michael Wojcik \\ Harri Latvakoski \\ Deron Scott \\ Mike Watson \\ Alan Marchant
}

See next page for additional authors

Follow this and additional works at: https://digitalcommons.usu.edu/sdl_pubs

\section{Recommended Citation}

Lwin, Maung; Wojcik, Michael; Latvakoski, Harri; Scott, Deron; Watson, Mike; Marchant, Alan; Topham, Shane; and Mlynczak, Martin, "Characterization of a Quantum Cascade Laser Based Emissivity Monitor for CORSAIR" (2011). Space Dynamics Lab Publications. Paper 146.

https://digitalcommons.usu.edu/sdl_pubs/146

This Article is brought to you for free and open access by the Space Dynamics Lab at DigitalCommons@USU. It has been accepted for inclusion in Space Dynamics Lab Publications by an authorized administrator of DigitalCommons@USU. For more information, please contact digitalcommons@usu.edu.

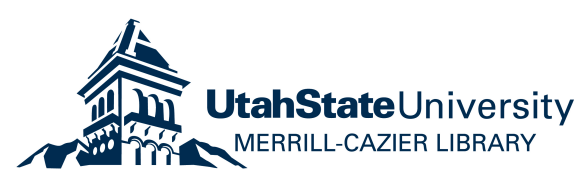




\section{Authors}

Maung Lwin, Michael Wojcik, Harri Latvakoski, Deron Scott, Mike Watson, Alan Marchant, Shane Topham, and Martin Mlynczak 


\title{
Characterization of a quantum cascade laser based emissivity monitor for CORSAIR
}

\author{
Maung Lwin ${ }^{1,2}$, Michael Wojcik ${ }^{2}$, Harri Latvakoski ${ }^{2}$, Deron Scott ${ }^{2}$, Mike Watson ${ }^{2}$, Alan Marchant ${ }^{2}$, \\ Shane Topham ${ }^{2}$, Martin Mlynczak ${ }^{3}$ \\ 1 - Princeton University, Princeton, NJ 08540 \\ 2 - Space Dynamics Laboratory, North Logan, UT 84341 \\ 3 - NASA Langley Research Center, Hampton, VA 23681
}

\begin{abstract}
Continuous improvements of quantum cascade laser (QCL) technology have extended the applications in environmental trace gas monitoring, mid-infrared spectroscopy in medicine and life science, law enforcement and homeland security and satellite sensor systems. We present the QCL based emissivity monitor for the CORSAIR blackbody. The emissivity of the blackbody was designed to be better than 0.9999 for the spectral range between 5 to $50 \mu \mathrm{m}$. To actively monitor changes in blackbody emissivity we employ a QCL-based infrared illumination source. The illumination source consisted of a QCL and thermoelectric cooler (TEC) unit mounted on a copper fixture. The stability of the QCL was measured for 30,60, and 90s operation time at 1.5A driving current. The temperature distribution along the laser mounting fixture and time dependent system heat dispersion were analyzed. The results were compared to radiative and conductive heat transfer models to define the potential laser operating time and required waiting time to return to initial temperature of the laser mount. The observed cooling behaviour is consistent with a primarily conductive heat transfer mechanism.
\end{abstract}

Keywords: On-board Calibration, Blackbody, Emissivity Monitor, Quantum Cascade Laser, Temperature Sensor, Heat Transfer

\section{INTRODUCTION}

The Calibrated Observation of Radiance Spectra from the Atmosphere in the Far-Infrared ${ }^{1}$ (CORSAIR) project was established to support NASA's Climate Absolute Radiance and Refractivity Observatory (CLARREO) mission. Space Dynamics Laboratory (SDL) is building a prototype blackbody (the CORSAIR blackbody) to demonstrate the ability to meet the precise CLARREO blackbody requirements, which includes the ability to monitor changes in the blackbody on orbit. This CORSAIR blackbody demonstrates the ability to recalibrate temperature sensors through the use of mini onorbit temperature recalibration (MOTR) hardware, software and methodology ${ }^{2}$ and the ability to detect changes in blackbody emissivity with an emissivity monitor. A straightforward method of monitoring emissivity is to illuminate the blackbody with a known source and observe changes in the signal from the blackbody. Because of the high emissivity of the CORSAIR blackbody, a thermal source that can produce a measurable change in signal for the CLARREO instrument must either be hot enough or observed for long enough that other affects will not confound the measurement. A better choice for the source is a QCL, which emits moderate output power (100's of $\mathrm{mW}$ ) in the mid-IR region. The QCL's small footprint (usually $\mathrm{mm}$ ) and ability to operate in room temperature (RT) (with thermoelectrically cooled (TE) cooling) allowed to design very compact, robust IR light source in a space environment.

\section{REQUIREMENTS FOR THE BLACKBODY AND EMISSIVITY MONITOR}

The main purpose of the blackbody design is to provide an isothermal cavity with a very accurate emissivity ${ }^{3}$. Table 1 presents the specification and requirements for the blackbody.

Infrared Technology and Applications XXXVII, edited by Bjørn F. Andresen, Gabor F. Fulop, Paul R. Norton, Proc. of SPIE Vol. 8012, 80123M - (c) 2011 SPIE · CCC code: 0277-786X/11/\$18 · doi: 10.1117/12.884260 
Table 1: Blackbody specification

\begin{tabular}{|l|l|}
\hline Parameters & Specification \\
\hline Blackbody temperature range & 100 to $350 \mathrm{~K}$ \\
\hline Operating environment & Ambient or inside larger vacuum chamber \\
\hline Coolant & $\mathrm{LN}_{2}$ \\
\hline Environment temperature & $77 \mathrm{~K}$ to ambient \\
\hline Blackbody aperture & $1.75 ”$ \\
\hline Beam divergence & $6($ full angle) \\
\hline Emissivity goal & 0.9999 (from 5 to $50 \mu \mathrm{m})$ \\
\hline Emissivity uncertainty goal & $\pm 0.00015(3 \sigma)$ \\
\hline Temperature sensor uncertainty goal & $\pm 25 \mathrm{mK}(3 \sigma)$ \\
\hline Uncertainty from gradients goal & $\pm 10 \mathrm{mK}(3 \sigma)$ \\
\hline
\end{tabular}

The objective of a CLARREO emissivity monitor is to monitor the emissivity on orbit to the level required. The emissivity that is of interest is the emissivity as seen by the instrument, which means the monitor should ideally observe the blackbody from the same location as the instrument, and illuminate the blackbody entrance from all angles. The former is simply accomplished by using the instrument to detect the signal (which also avoids another detector). The latter can't be achieved completely, but is simple to approximate by just shining the wide beam of a QCL into the blackbody through a small entrance hole near the aperture.

As shown in Figure 1, largely diverged QCL beam (red) is shining into the blackbody cavity through a small entrance hole and the instrument collects the radiance (blue) emitted from the blackbody. A uniform source of illumination outside the blackbody (green) is also shown in the figure.

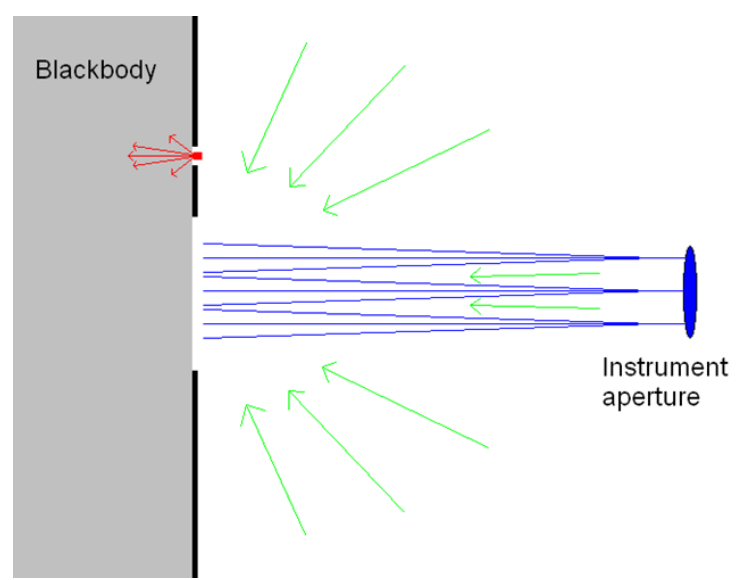

Fig.1: Emissivity monitor concept including a blackbody cavity, an IR light source and a detector (signal collecting instrument) 


\section{THEORETICAL BACKGROUND}

\subsection{Emissivity monitor}

A perfect blackbody (emissivity, $\varepsilon=1$ ) absorbs all incoming radiations, but some radiation can be detected from the blackbody with $\varepsilon<1$. Figure 2 shows the calculated radiance seen by an instrument observing the CORSAIR blackbody when the QCL emits the IR radiation onto the blackbody for different emissivity values, 0.999, 0.9999 and 0.99999.

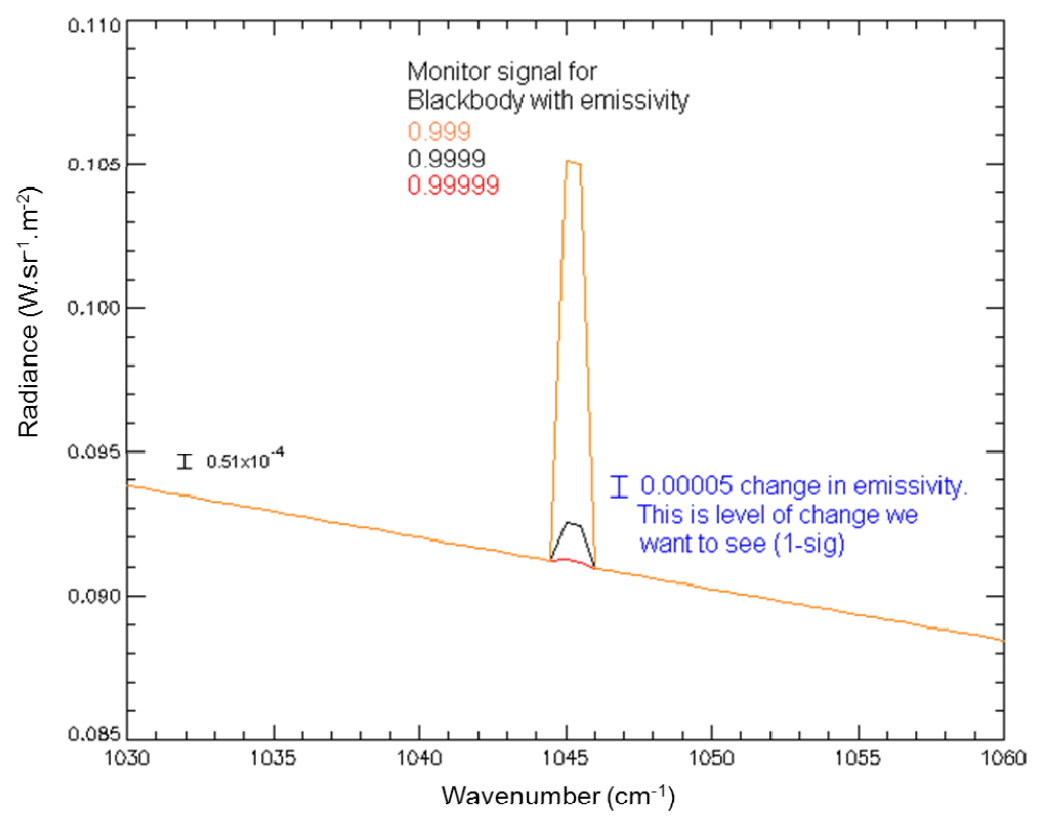

Fig. 2 Modeled radiance values on the instrument detector when the QCL emits the IR radiation onto the blackbody and blackbody absorbs most of the radiation under different emissivity values. From top to bottom, the emissivities are 0.999 (orange), 0.999

(black), and 0.99999 (red).

\subsection{Temperature distribution on the QCL mount}

Thermally dissipated power by the laser generates heat on the laser mount and understanding it allows us to design heatsink and define the duty cycle of laser operation. Using a TEC on the QCL mount reduces the temperature, $\mathrm{T}_{\max }$, of the heat sink and the heat transfer model was used to calculate required time to return initial temperature of the laser mount from $\mathrm{T}_{\max }$.

The temperature distribution on the copper heat sink can be calculated using the heat transfer equations ${ }^{4}$ as the modes of conduction and radiation shown in Equation 1 and 2.

$$
\frac{Q}{t}=\frac{k A \Delta T}{d}
$$

where $Q$ is heat transfer in time $t, k$ is thermal conductivity, $A$ is cross-section area, $\Delta T$ is temperature different between heat-sink temperature and surrounding temperature, and $d$ is the thickness of the heat-sink.

For heat transfer due to radiation:

$$
P=\varepsilon \sigma A\left(T^{4}-T_{s}{ }^{4}\right)
$$

where $P$ is net radiated power, $\varepsilon$ is emissivity, $\sigma$ is Stefan's constant, $A$ is radiating area, $T$ is heat-sink temperature and $T_{s}$ is surrounding temperature. Finally we calculate time and location depended temperature as following. 


$$
T(x, t)=T_{0}(x)+\Delta T_{0} e^{t / \tau}
$$

where $\mathrm{T}_{0}$ initial temperature at $\mathrm{x}, \Delta \mathrm{T}_{0}$ is initial temperature different, and $\tau$ is time constant.

\section{IMPLEMENTATION OF THE QCL}

The QCL mounting fixture and heat spreader were machined from copper 101. A TEC element is used for active laser temperature control. The larger copper piece is attached directly to the vacuum flange which contains a multipin vacuum electrical feedthrough. (see Fig. 3). The emission from the front facet of the QCL is injected into the blackbody cavity through a small hole. The QCL that was used was a Fabry-Perot device and did not have a high reflection coating on the rear facet, so emission from the rear facet of the laser was sent to a beam dump and did not enter the blackbody.

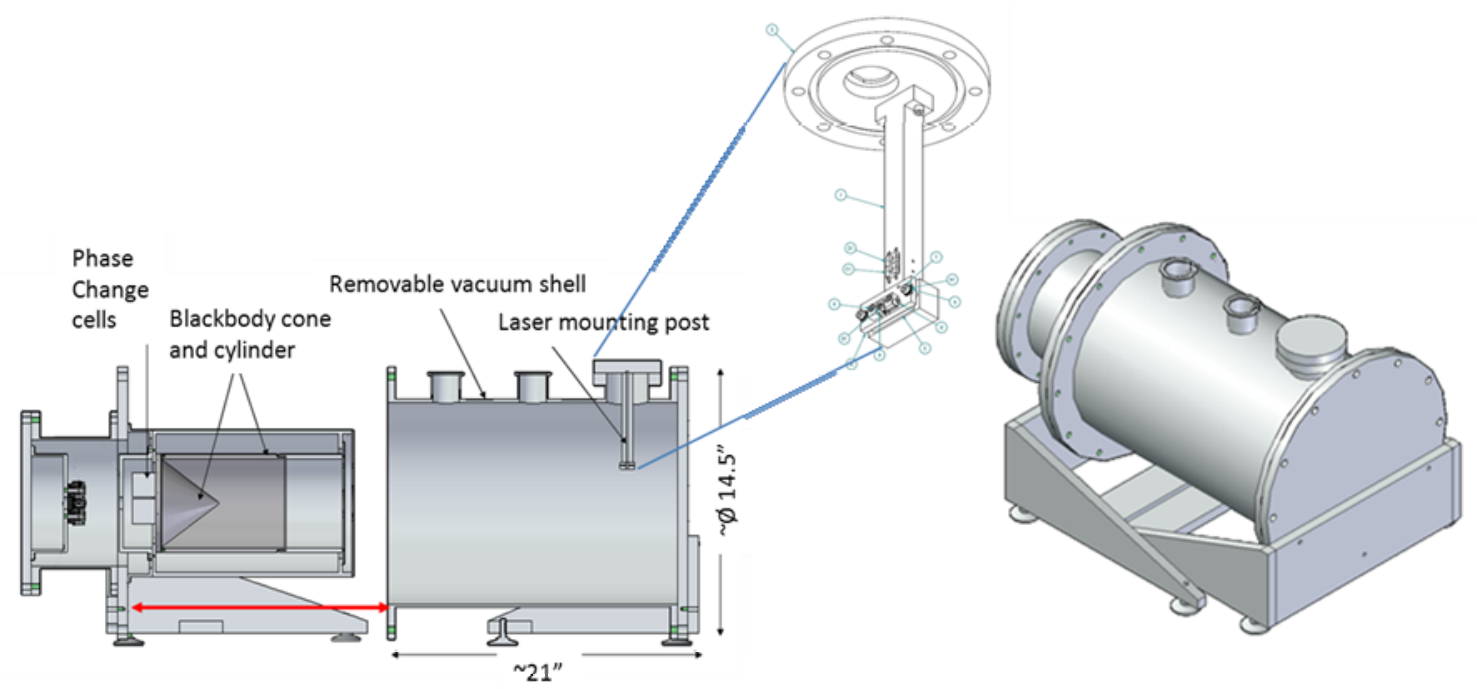

Fig.3: Blackbody section view illustrating emissivity monitor with the QCL

\section{EXPERIMENTAL SETUP}

The experimental arrangements of the QCL output power stability measurement and heat distribution measurements along the copper heat sink are shown in Figures 4a, 4b and 4c. In Figure 4a, the QCL (AdTech Optics) emitted frequency of $9.5 \mu \mathrm{m}$ was installed on small copper heat spreader. The TEC module was placed between the heat spreader and larger heat-sink block. All copper parts were fabricated from Cu101. A protective shroud machined from G10 was used to surround the QCL to prevent direct mechanical contact of the laser with other blackbody components. The SP-60 thermistor (long-term stability with $\sim 1 \mathrm{mK}$ variation) was attached on the QCL mount. The QCL was operated using Arroyo instruments TECSource 5310 and LaserSource 4302. The QCL beam was directed onto the S310C thermal sensor and collected data with PM 100D digital optical power meter (both from Thorlabs). For heat distribution measurements, 3 thermocouples were attached back of the copper heat sink as shown in Figure 4c. 


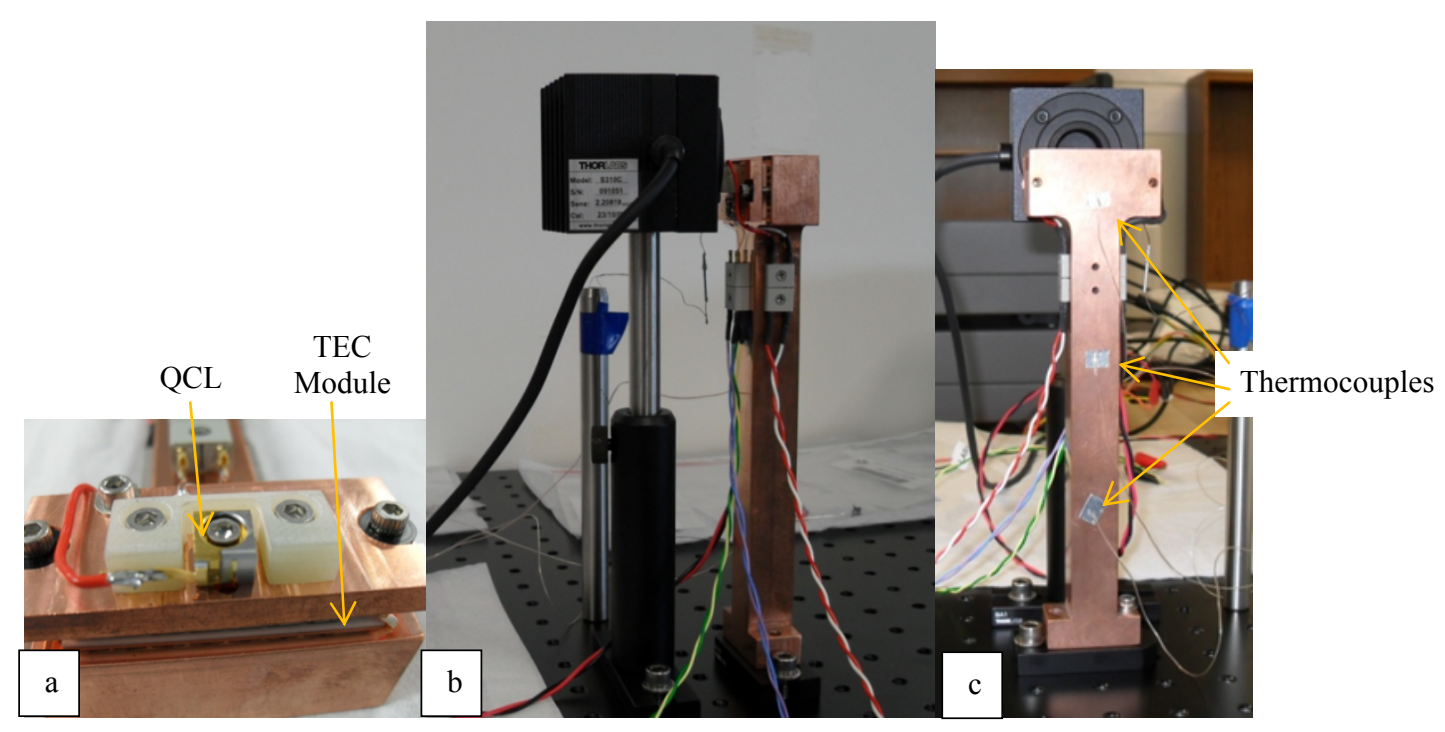

Fig. 4: Assembly and experimental setup for the QCL power stability measurement and thermal testing

\section{PRELIMINARY RESULTS AND DISCUSSION}

The output power of the front facet of QCL for $60 \mathrm{~s}$ operating time at $1.5 \mathrm{~A}$ driving current is shown in Figure 5 . The average output power calculated for stable laser operation time was $115.6 \pm 0.56 \mathrm{~mW}(1 \sigma)$.

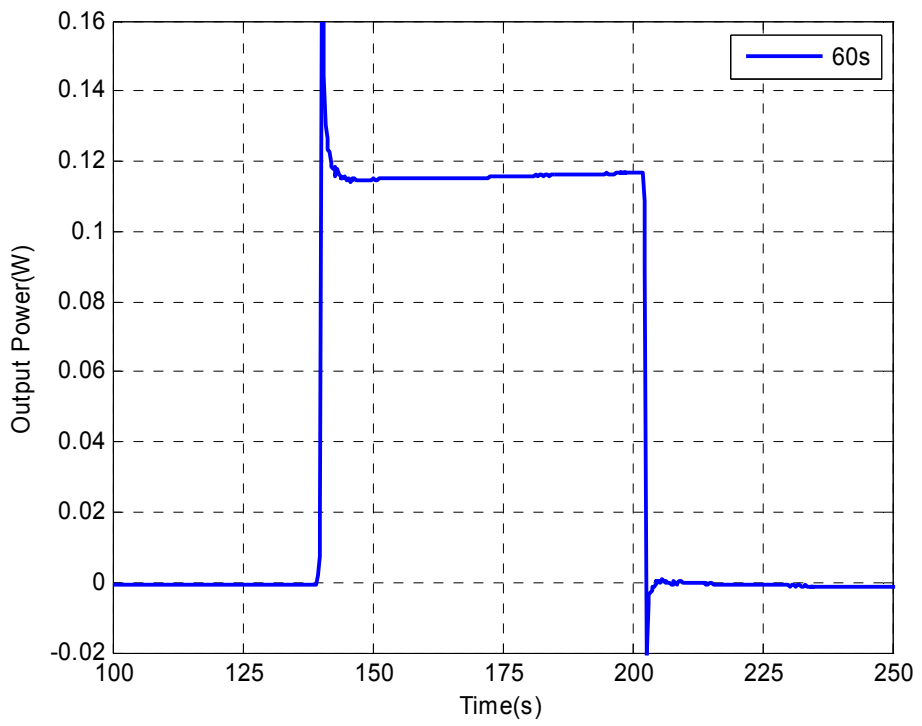

Fig. 5: The QCL output power as function of time

The QCL mount temperature increased to $24.7,27.3$ and $32.1{ }^{\circ} \mathrm{C}$ from the initial temperature of $22^{\circ} \mathrm{C}$ after the QCL was turned on for 30,60 and 90s respectively. As shown in Figure 6, the required time to return room temperature from its 
maximum temperatures are less than $30 \mathrm{~min}$ for $30 \mathrm{~s}$, and $60 \mathrm{~s}$ laser running times and less than $45 \mathrm{~min}$ for $90 \mathrm{~s}$ laser running time.

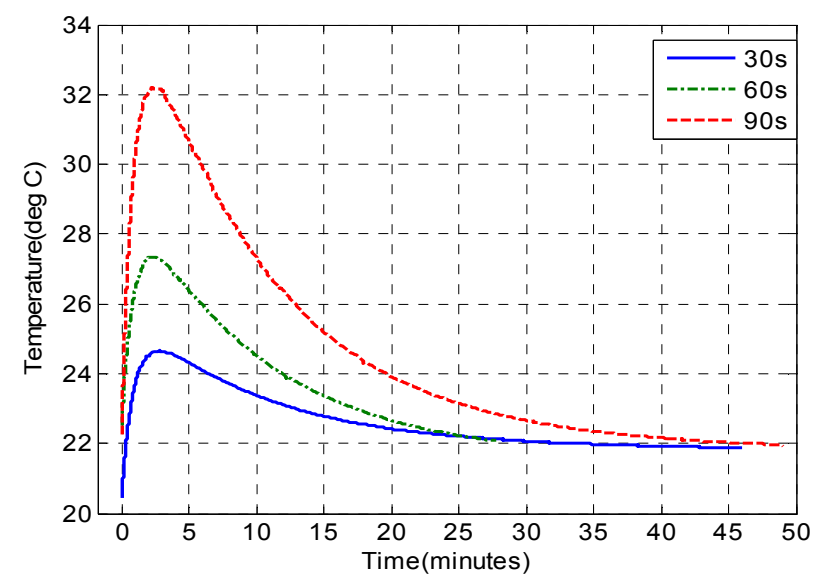

Fig. 6: Temperature curve at the QCL heat spreader plate after 30, 60 and 90s operating time

The temperature on the heat-sink was larger than laser mount temperature as hot-face of TEC was touching on the heatsink. As shown in Figure 7 the maximum heat-sink temperature reached to $47^{\circ} \mathrm{C}$ for 90 s operation time and it needed $\sim 50 \mathrm{~min}$ to cool down to the room temperature. The increased temperature decreased from $26^{\circ} \mathrm{C}$ to $8^{\circ} \mathrm{C}$ when the laser running time changed form 90 s to $30 \mathrm{~s}$.

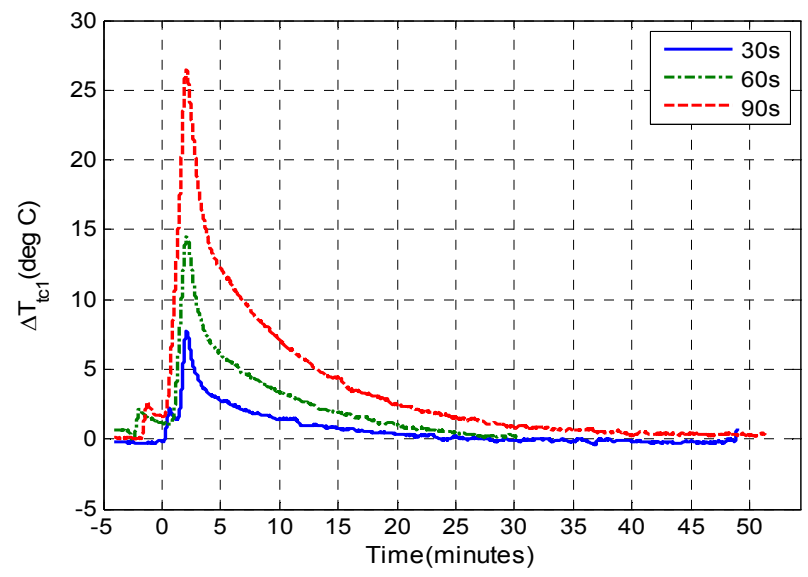

Fig. 7: Temperature increase on the heat-sink close to the laser as the function of time after 30,60 and 90 s laser operating time

We compared the above results to the heat transfer model explained in section 3.2. From calculation using our heat-sink parameters, the heat dissipation rate by conduction is 2 orders of magnitude higher than the heat dissipation by radiation. Both measured temperatures and model temperatures of the QCL sub-mount are shown in Figure. 8. The results from the model have a very good agreement with the measurement in $<0.5^{\circ} \mathrm{C}$ difference for the range between 22 and $32^{\circ} \mathrm{C}$. 


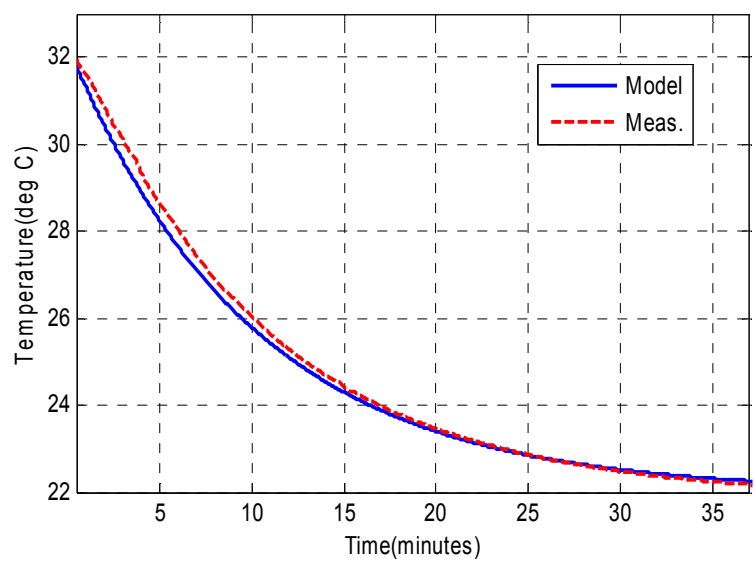

Fig. 8: Comparison of QCL sub-mount temperatures from the measurements and the model results

\section{CONCLUSIONS}

We have demonstrated the operation of a QCL for use in monitoring emissivity. The integration of the QCL in the blackbody design is explained. Moreover, the temperature distribution at the laser mount was analyzed in the context of a conductive heat transfer model. The results show that the emissivity monitor can easily operate hourly with a QCL running time up to $90 \mathrm{~s}$. Immediate future efforts will be to document the operational performance of this QCL-based emissivity monitoring technology on the CORSAIR blackbody.

\section{ACKNOWLEDGMENTS}

This project was performed in cooperation with the Utah State University Research Foundation, Space Dynamics Laboratory, and NASA Langley Research Center. The CORSAIR Instrument Incubator Program is sponsored by the NASA Earth Science Technology Office.. ML would like to gratefully thank the National Science Foundation Center for Mid-Infrared Technologies for Health and the Environment (MIRTHE) for support during this project.

\section{REFERENCES}

[1] Harries, J., Carli, B., Rizzi, R., Serio, C., Mlynczak, M., Palchetti, L., Maestri, T., Brindley, H., and Masiello, G., "The Far-Infrared Earth", Rev. Geophy., 46 (2008).

[2] Latvakoski, H., Watson, M., Topham, S., Scott, D., Wojcik, M., Bingham, G., "A high-accuracy blackbody for CLARREO", Proc. SPIE 7808, 78080X (2010).

[3] Best, A., et al., "The Geosynchronous Imaging Fourier Transform Spectrometer (GIFT) On-board Blackbody Calibration System", Proc. SPIE 5655, 77-87 (2005).

[4] Lienhard IV, J., and Lienhard V, J., “A Heat Transfer Textbook”, $4^{\text {th }}$ Ed., Phlogiston Press, Cambridge, 10-26 (2011). 